\title{
Factors Influencing Self-esteem of Indian Female Adolescents
}

\author{
Megha Dhillon ${ }^{1}$, Priti Dhawan ${ }^{2,}$ Kanika Ahuja $^{3,}$ Kalyani A..' Deepika Papneja ${ }^{5}$ \\ ${ }^{\prime}$ (Psychology Department, LSR College/ Delhi University, India) \\ ${ }_{2}^{2}$ (Psychology Department, LSR College/ Delhi University, India) \\ ${ }^{3}$ (Psychology Department, LSR College/ Delhi University, India) \\ ${ }^{4}$ (Elementary Education Department, LSR College/ Delhi University, India) \\ 5 (Elementary Education Department, LSR College/ Delhi University, India)
}

\begin{abstract}
Much research has been conducted on self-esteem, although mainly in the West. Findings indicate that self-esteem drops sharply in adolescence, more so in girls than boys. Self-esteem is an important determinant of adolescent mental health. Many programs have been created abroad that focus on self-esteem enhancement in adolescents. However interventions developed in the West cannot be implemented in India without modification, given the socio-cultural differences. This study is an attempt to develop an intervention that is apt for the Indian context. As a step in developing such interventions we sought to identify factors that shape the self-esteem of adolescent girls. In-depth interviews were conducted with 32 girls between the ages of 14 and 16 years studying in four government co-educational schools. 17 girls were identified as having high self-esteem while 15 were identified as having low self-esteem. Poor academic self-efficacy, teasing by peers, dissatisfaction with physical appearance, family conflict and gender discrimination in the family were found linked to low self-esteem. On the other hand satisfaction with academic performance and lesser tendency for social comparison were found to be linked with high self-esteem. How this information may contribute in creating an intervention for adolescent girls is further discussed.
\end{abstract}

Keywords - Adolescents, female, Indian, intervention, self-esteem

\section{INTRODUCTION}

Self-esteem is one of psychology's most well-known constructs. This term has been defined in several ways. One of the most well-known theorists in the area, Morris Rosenberg, [1] defined self-esteem as a favorable or unfavorable attitude towards the self. Korman [2] states that self-esteem reflects the degree to which the individual "sees himself as a competent, need-satisfying individual" and that persons with high self-esteem feel a sense of personal adequacy and believe that they have achieved satisfaction of their needs in the past. Guindon [3] stated that self-esteem refers to the attitudinal and evaluative component of the self. It involves feelings of worth and acceptance which are developed as a result of the awareness of our competencies and feedback from the world around us. Emerging as common across most definitions of self-esteem is the component of selfevaluation. This self-evaluative process is seen to be part of but distinct from one's self-concept which also includes cognitive and behavioral aspects of the self [4].

Much research has been conducted on self-esteem. This research has identified clear age-related patterns. In a study on self-esteem across the life span Robins et al [5] found that while self-esteem levels were high in childhood, they dropped during adolescence and rose gradually throughout adulthood, once again declining in old age. This trajectory generally held true across gender, socio-economic status, ethnicity and nationality. Adolescence therefore emerges as a time of reduction in self-esteem. A study by Dhal, Bhatia, Sharma and Gupta [6] in Delhi found that adolescents aged 12-13 years reported lower self-esteem that those aged 10-11 years. The decline in self-esteem that occurs at this time is a result of many changes the adolescent experiences. Bos, Muris, Mulkens and Schaalma [7] identify four major changes that take place in adolescence. Firstly, this is a time when boys and girls develop secondary sexual characteristics. In addition, they acquire the capacity of formative thought, enabling them to think about phenomena in far more complex ways than earlier. Socially as well as emotionally this is a period when adolescents start to spend less time with their families and move towards peers. Friendship and romantic relationships often take precedence over family. Difficulty in being accepted by peers and relationship failures can leave adolescents vulnerable to feelings of social inadequacy [8]. Finally, adolescents may experience school transitions, which in itself can be stressful.

Another significant trend is that of gender differences. Robins and Trzesniewski [9] state that boys and girls report similar levels of self-esteem during childhood, but a gender gap emerges by adolescence, such that adolescent boys have higher self-esteem than adolescent girls [10; 5] Robins et al., 2002). A study by Watkins, Dong and Xia [11] on 10 and 13-year-old children attending Beijing public schools found that older 
boys and older girls reported less favorable self-esteem than their younger peers on the scales for reading and school in general. The older girls tended to report significantly lower self-esteem than both the younger girls and older boys in the areas of physical abilities, reading, mathematics, and general self-concept. Indian studies have shown similar results with adolescent males showing higher self-esteem than females [12]. Lower self-esteem among girls has been attributed to several reasons including less favorable attitudes towards their gender roles [13] and more concerns about appearance [14], although boys seem to be showing increasing amounts of concern as well.

In general a number of factors impact the development of self-esteem. Schools and educational experiences are central to the development of self esteem. Jain and Dixit [15] found the most prominent cause for reduction in self-esteem among Indian youth to be the inability to meet academic expectations of others as well as the self. On the other hand, good teachers are likely to enhance self-esteem by fostering academic achievement $[16 ; 17]$. In addition, parent-child relationships including adolescent perceptions of communication and participation with parents are a significant factor [18].Within the Indian context, Deshpande and Chhabriya [19] found that adolescents who perceive acceptance from their parents have higher self-esteem than adolescents who perceive avoidance. Social experiences of childhood and adolescence which include the development of peer relations also influence the development of self-esteem. Peers can serve a significant role when adolescents find parental support to be lacking. For instance, in a study on maltreated adolescents Bolger et al. [20] found that friendship quality had a protective-stabilizing effect on global self-esteem development.

Self-esteem has been linked to a number of mental health outcomes. Furnham and Cheng [21] found self-esteem to be both a direct and a moderator variable for young people's self-reported happiness. It is also associated with life satisfaction [22]. On the contrary, low self-esteem is associated with a number of negative outcomes including membership in deviant groups and aggression towards peers [cited 23]. It is also linked to eating disorders [24], depression and anxiety [25]. A study by Bolognini, Plancherel, Bettschart and Halfon [26] found that low self-esteem was correlated with depressive moods in both adolescent boys and girls, however low levels of self-esteem had more influence on the level of depressive mood in girls than in boys. Moreover loneliness and self-esteem are negatively correlated [27].

Interventions for enhancing self-esteem: Given the negative outcomes associated with low self-esteem a number of interventions have been created for self-esteem enhancement in young people. Interventions that are social and cognitive in nature have been found to be very effective. Barrett, Webster and Wallis [28] developed a school-based psycho-social prevention program for adolescents, focusing on self-esteem, negative cognitive processes, and peer isolation. Students between the ages of 13-16 years were randomly allocated to one of three groups; Social Cognitive Training group (SCT), Attention Placebo Comparison Group (APC) and a Waitlist Control group (WL). Results showed significant improvements on measures of target skills for the SCT group in contrast to the comparison conditions on reported self-esteem, and self statements, however mixed results were found on the impact measures. Student self-report ratings of quality of peer relationships showed little change across the study period. Haney and Durlak [29] conducted a meta-analytic review of 116 studies pertaining to self-esteem enhancement interventions, which indicated significant improvement in children's and adolescents' self-esteem, and significant changes in behavioral, personality, and academic functioning. However the effectiveness of interventions varied depending type, focus and the extent to which they were theory and evidence-based.

Despite research identifying self-esteem as an important area to target with adolescents, interventions for enhancing self-worth have not received much attention in India. Modules developed in the West cannot be implemented here without modification, given the social and cultural differences between the two settings. Work within this area is recent and limited. In one such study Sharma and Agarwala [30] studied the effectiveness of a behavioural intervention program in enhancing self-esteem among persons aged 17-23 years. Participants low on self-esteem received a three month intervention that involved parents and teachers in the process. Teachers and parents were encouraged to be supportive and provide adolescents with opportunities for expression. Researchers also met each subject at least twice a week and talked about his/her performance and achievements. They also encouraged subjects to focus on solutions rather than on problems and convert negative thoughts to positive ones. The results showed a significant difference between pre-intervention and postintervention self-esteem scores. In another study Dani [31] implemented a self-esteem enhancement intervention with boys and girls of the 8th and 9th standard. Students with low self-esteem were divided into experimental and control groups randomly. The experimental group was given the intervention module for 15 sessions; each session lasted for 45 minutes. Significant differences were obtained between the pre-test and post-test means for the experimental group. No significant difference was observed between the pre-test and post-test means of the control group.

The present study is another step on the path to creating an intervention that is low cost, locally based and apt for the Indian educational context. For this study we chose to focus on adolescent girls considering the large amount of research showing that during adolescence girls tend to have lower self-esteem than boys. 
Schools were chosen as the site of study given their significance for adolescent social and emotional development. In order to begin the process of developing the modules we felt it was necessary to collect first hand information on the factors shaping the self-esteem of adolescent girls from our target population, although some research has already been conducted in the area. This paper presents the findings obtained in the initial phase of the study. The other phases which are still underway include designing, implementation and assessment of the modules for self-esteem enhancement.

\section{METHOD}

2.1 Sample

In-depth semi-structured interviews were conducted with 32 girls (17 girls with high self-esteem and 15 with low self-esteem) between the ages of 14 and 16 years, studying in class IX, X or XI. The participants were selected from four government co-educational schools in South Delhi through purposive sampling. The sample belonged mainly to middle income families.

\subsection{Tools}

Interview schedule. A semi-structured interview schedule was devised by the researchers to tap into factors effecting the self-esteem of adolescent girls. The domains covered in the interview were identified through a review of studies conducted in the area of adolescent self-esteem. Questions were formulated and then re-phrased or revised, till all the questions appeared appropriate for the purpose of the study. It was ensured that the questions were simple, direct and mostly open-ended. The schedule was created in English and Hindi. The language eventually used depended on the preference on the participant.

\subsection{Procedure}

A total of 358 females between the ages of 14 and 16 years, drawn from four different schools, were administered the Rosenberg Self-esteem Questionnaire (RSQ). The RSQ is a ten-item Likert-type scale measuring global self-esteem, with items answered on a four-point scale — from strongly agree to strongly disagree. The scale generally has high reliability: test-retest correlations are typically in the range of .82 to .88 , and Cronbach's alpha for various samples are in the range of .77 to .88 [4; 32]. In the present study, all questionnaires were scored and a group mean was computed (mean=18.15, SD=4.12). Scores within 1 standard deviation of the mean were designated as average. Those below 1 standard deviation of the mean (14.02) were designated as 'lower than average' while scores above 1 standard deviation of the mean (22.27) were designated as 'higher than average.' Participants in these two groups were invited for interviews. All those who were invited agreed to be interviewed. All interviews were conducted face to face, on school premises although in spaces that offered privacy and were audio-recorded with the consent of the participants.

\subsection{Analysis}

First, within each set, every interview was read and re-read whole in order to comprehend its essence and tone. The idea was to obtain a holistic perspective on the experiences of each participant. After all the interviews had been read at least once, similarities and differences within each set of interviews were identified. Then initial themes were delineated, organized into clusters and checked against the data. Each theme was given a descriptive label. Themes were then refined, condensed and examined for interconnections. The final themes and sub-themes that emerged were then put together.

\section{RESULTS AND DISCUSSION}

The themes that emerged from the interviews are presented below.

Role of parents. Given the crucial role that parents play in the development of self-esteem [33] participants were asked about the nature of the relationship they shared with their parents as well as the expectations their parents had from them. Nearly all the adolescents (94.4\% participants of the high self-esteem group and $85.71 \%$ participants of the low self-esteem group) reported that their parents had clear and high expectations from them mainly with respect to academics. For example one girl with low self-esteem reported that her parents wanted her to select the science stream and then take admission in IIT. Another participant with high self-esteem reported that her parents wanted her to study very hard and raise the name of her family to great heights. Parental expectations were not always in line with what adolescents aspired to do with their lives. One participant with low self-esteem said "My parents want me to take commerce but I don't want that. I want to model and act."

Nevertheless, participants reported taking these expectations very seriously. However they were generally afraid of failing to meet them. Unsurprisingly only $21.43 \%$ adolescents from the low self-esteem group reported feeling confident that they would meet parental expectations. This was lesser than the high selfesteem group where $44.44 \%$ participants said they felt confident of being able to meet parents' expectations. 
This notwithstanding, the majority of participants in both groups expressed low confidence in context of standards set by their parents.

Another similarity across groups was the parental tendency to make comparisons with peers, siblings and cousins. The number of participants reporting such comparisons was only marginally more in the low selfesteem group $(57.24 \%)$ than in the high self-esteem group $(50 \%)$. Once again academics emerged as the most dominant field of social comparison by parents. Social comparisons were also made when it came to shopping habits and willingness to engage in household chores. Some adolescents talked about disliking the comparisons. For instance a participant low on self-esteem said "I don't like (the comparisons). I am Sapna, I am not Surbhi." Another girl with high self-esteem explained "I tell mummy not to compare. Then a fight happens. Then we don't talk to each other."

Some differences emerged in terms of quality of relationship. Results indicated that $77.77 \%$ of those in the high self-esteem group reported sharing good relationships with their parents as compared to $57.14 \%$ participants in the low self-esteem group. One participant with low self-esteem described her changed relationship with her father saying "When I was younger, I used to study normally...then I was very friendly with my father. But now if he says anything I get very irritated." On the other hand participants with low self-esteem also described relations with their parents saying "Our relations are good" and "I think they are the best parents in the world." There was some difference with respect to instances of family conflicts and gender discrimination within the family. Among students with low self-esteem, 37.5\% reported that there had been conflicts in their families. This percentage was smaller $(11.11 \%)$ in the high self-esteem group. Most conflicts were reported to have taken place in context of the extended family except for two students with low self-esteem who reported conflict between parents. Also more students with low self-esteem (31.25\%) reported experiencing gender discrimination by family members than those with high self-esteem $(11.11 \%)$. Gender discrimination is likely to be a factor diminishing the self-esteem of girls in all cultures with male preferences and patriarchal set-ups. In line with this Siah [34] conducted a study in China and found that perceived parental sex discrimination was negatively correlated with happiness and self-esteem. Importantly, this relationship only occurred among females, not males. Given such research, this is specifically an aspect that interventions tailored to the Indian context must look into.

School. The participants generally reported school to play a significant role in their lives. When asked about their academic performance, students with high self-esteem differed considerably from those with low self esteem. It was seen that $83.33 \%$ students with high self-esteem believed that their academic performance was good. Only $7.14 \%$ of the students with low self-esteem reported so. One participant with low self-esteem explained her academic performance saying "Average...bad...teachers teach everything...there is some lack from our side." We did not assess the actual academic performance of the participants, however it seems clear that perceptions of academic performance play a very significant role in Indian adolescents' levels of selfesteem and this needs to be a significant area of focus for any long term intervention. Some differences, although not as large as academics were also found for participation in extra-curricular activities. More students with high self-esteem $(77.77 \%)$ reported active participation in school activities than students with low selfesteem (50\%). The difference may be lower here due to the reduced emphasis in the Indian education system on extra-curricular participation as compared to academic excellence.

Although asked specifically about the role of teachers in shaping their opinions about themselves, the participants did not share much. Much to our surprise, many participants reported teachers as playing no role in this regard. Only $55.56 \%$ of the students from the high self-esteem and $28.57 \%$ students from the low selfesteem group agreed that teachers have shaped the way they felt about themselves. Among those who acknowledged the role of teachers, mixed opinions emerged. While some spoke of teachers as inspiring and caring, others narrated instances where the impact of teachers had been negative. Given that teachers clearly affect the way students feel [35] the difficulty faced in eliciting information may have been a result of reluctance among the participants (especially those with low self-esteem) to say anything about their teachers to outsiders, despite efforts on our part to develop rapport before the interviews and assure confidentiality.

Role of peers. Peer relationships have been identified as an extremely significant context for adolescent development. Peers serve as sources of emotional support and security. Birkeland, Breivik, and Wold [36] found that peer acceptance has a protective-stabilizing effect on the relationship between closeness to parents and global self-esteem. Litwack, Aikins and Cillessen [37] found that perceived popularity among peers is uniquely related to decreases in depressive affect and increases in adolescent self-esteem. Results of this study indicated that more students in the high self-esteem group felt they were important to their friends and reported greater ease in making friends. However even in the low self esteem group, every participant reported having at least one friend they could share their problems with. A larger difference was found with respect to instances of teasing. For instance $27.77 \%$ students from the high self-esteem group said that had faced teasing in the forms of name-calling and spreading of rumours. This percentage was clearly higher in the group with low self esteem $(57.14 \%)$. An issue over which teasing was reported to take place was physical appearance. One participant with 
low self esteem explained "Everyone teases me. As a joke and seriously also. Both my parents are short in height, so I will of course also be short in height. This, they don't understand. But one does feel bad." Another participant with low self-esteem spoke of dieting after being teased for her weight, leading to serious health consequences. She said "They used to tease me about being fat..one time I dieted and then got admitted in hospital. I would skip my food...doctor said hemoglobin became low."

Body-esteem issues. This is one area which has not been focused upon in research on self esteem conducted within the Indian setting. However it deserves attention due to two reasons. Firstly previous studies have found a link between body dissatisfaction and self-esteem in adolescence [38]. Secondly body dissatisfaction problems are common among urban Indian adolescent females [39]. In the present study $71.43 \%$ of girls with low selfesteem said that they were unhappy with their physical appearance. For example one girl said "I don't like my appearance and all. I want that I should become ok, like normal girls...like they are pretty, I should also become pretty." Another girl said "I want to change my height and my hair. I don't like them." In contrast a much smaller number of participants $(22.22 \%)$ in the high self-esteem group reported such issues. Body image issues in turn have been found to effect peer relationships. According to Davidson \& McCabe [40] poor body image may hamper adolescents' development of interpersonal skills and positive relations with peers. Physical attractiveness can impact peer relationships in elementary school, with attractive girls engaging in more positive social interactions than less-attractive girls. Body image issues are particularly important for female adolescents given the multiple changes their bodies go through around puberty including weight gain and the development of acne. Furthermore, it appears that the body changes that happen during puberty can be more of a struggle for females than for boys [40].

Comparisons with others. Social comparison theory [41] suggests that individuals compare themselves to others when they require an external standard against which to assess their abilities or notions. In the present study, there was a stark difference between the high self-esteem group and the low self-esteem group with respect to propensity for upward social comparisons, with $71.43 \%$ of the students from the low self-esteem group agreeing that they engage in the same frequently and only $22.22 \%$ from the high self-esteem group reporting so. Gibbons and Buunk [42] found that the tendency to use social comparisons for self evaluation is correlated with low self-esteem, depression and neuroticism. Interviews indicated that participants with low selfesteem mainly engaged in social comparisons in terms of academic performance and physical appearance. One respondent said "In studies...I want to be like (high performing peers). Papa also says this... if they are doing it, I also want to do it." Buunk, Kuyper and Van der Zee [43] also found that high school students often compared themselves to peers who had received higher grades in the hope of receiving similar grades in future. Upward social comparisons, although sometimes contribute to self-esteem, may not be successful in doing so when it comes to individuals with low self-esteem. Aspinwall and Taylor [44] found that upward social comparisons were beneficial in circumstances where the individuals engaging in the comparisons had high self-esteem, because these types of comparisons provided them with motivation and hope. However, if these individuals had experienced a recent threat or setback to their self-esteem, they reported that upward comparisons resulted in a more negative affect than downward comparisons.

Strategies for self esteem maintenance. The interviews indicated that girls with a high self-esteem used different strategies to maintain their self worth. These included accepting and working on weakness, negating poor outcomes (for example by minimizing their significance in one's life) surrounding themselves with supportive people and ignoring criticism. One participant from the high self-esteem group explained "If someone says something bad, I don't pay much attention." They also reported re-framing the negative and positive. For instance one girl with high self-esteem said "I feel good when others compliment me. I also feel good when they criticize me...they must be criticizing me because they are jealous of me." These strategies were found to be missing from the interviews of those with low self-esteem. The findings indicate a need for interventions that challenge thinking styles in adolescents that contribute to the maintenance of low self-esteem.

\section{CONCLUSION}

The purpose of the study was to identify factors shaping the self-esteem of adolescent girls. Some clear differences identified through the interviews with students having high and low self -esteem, have helped us map certain areas of emphasis for designing interventions. One of the most significant areas that emerged is academic self-efficacy. This would require enabling students to identify their academic fortes and weaknesses and develop study habits by which weaknesses can be overcome in manners that are not stressful for the adolescent. However this is one area in which work with parents would be required as a great deal of academic stress appears to stem from parental expectations. Parental involvement would also be needed to combat gender discrimination and its effects on self-esteem. Within the school, despite the limited emphasis on extra-curricular engagement, it is necessary to encourage students with low self-esteem to participate in these activities, although in a supportive and encouraging environment. In terms of intra-personal and inter-personal development, several areas have appeared as significant. These include developing skills of assertiveness to counter teasing from 
peers, learning cognitive re-framing, engaging in realistic and limited social comparisons and focussing on success rather than failure. We also sensed reluctance in many students with low self-esteem to identify their strengths. Developing a balanced view of one's strengths (including of physical appearance) may be a key component of such interventions. While workshops may be a good arena to address these issues, any long lasting enhancements in self-esteem would require input from teachers. Therefore sensitizing teachers to these issues and providing them the space to focus on adolescents' psychological development is of utmost importance. However given the tremendous academic pressure under which schools function, this may be a significant challenge in the long term implementation of interventions.

V. Some limitations of the study must be acknowledged. The sample of the study was small and nonrepresentative. Results therefore cannot be generalised to all female adolescents. Social desirability bias could have affected the interviews as could have the fact that each participant was met with only once. More than one meeting with each adolescent may have generated richer data. Also several factors that could effect self-esteem including minority status, socio-economic strata and sexuality were not discussed and it is imperative that future studies engage with these areas.

\section{ACKNOWLEDGEMENTS}

This research was supported by a grant given by the University of Delhi under the Innovation Research Project Scheme (2015-2016). We would like to express our deep appreciation to Dr. Nandita Babu, Professor and Head of Department of Psychology at the University of Delhi for her support in carrying out the project. We would also like to extend a thanks to the ten student research associates (Tushali Paliwal, Charul Katiyar, Vaidehi Mishra, Sana Jamal, Anjana Dhaiya, Kriti Singh, Aditi Suryavanshi, Rose Pauline Bara, Shazia Naqvi and Himanshi Piplani) who played an invaluable role in shaping the study, collecting data from the field and analyzing it.

\section{REFERENCES}

1. M. Rosenberg, Society and adolescent self image (New York: Basic Books, 1965).

2. A. K. Korman, Toward a hypothesis of work behavior, Journal of Applied Psychology, 54(1p1), 1970, 31.

3. M.H. Guindon, Toward accountability in the use of the self-esteem construct. Journal of Counseling \& Development , 80(2), 2002, 204-214.

4. J. Blascovich and J. Tomaka, Measures of self-esteem, in J. P. Robinson and P. R. Shaver (Eds.), Measures of Personality and Social Psychological Attitudes (San Diego, CA: Academic Press, 1991) $115-160$.

5. R. W. Robins, K. H. Trzesniewski, J. L Tracy, S. D. Gosling, and J. Potter, Global self-esteem across the life span, Psychology and Aging, 17, 2002, 423-434.

6. A. Dhal, S. Bhatia, V. Sharma, and P. Gupta, Adolescent self-esteem, attachment and loneliness. Journal of Indian Association for Child and Adolescent Mental Health, 3(3), 2007, 61-63.

7. A. E. R. Bos, P. Muris, S. Mulkens, and H. P. Schaalma, Changing self-esteem in children and adolescents: A roadmap for future interventions. Netherlands Journal of Psychology, 62(1), 2006, 2633.

8. M. R. Leary, and R. F. Baumeister, The nature and function of self-esteem: Sociometer theory. Advances in Experimental Social Psychology, 32, 2000, 1-62.

9. R.W. Robins, and K.H. Trzesniewski, Self-esteem development across the lifespan. Current Directions in Psychological Science, 14(3), 2005, 158-162.

10. K. C. Kling, J. S. Hyde, C. J. Showers, and B.N. Buswell, B. Gender differences in self-esteem: a metaanalysis. Psychological Bulletin, 125(4), 1999, 470.

11. D. Watkins, Q. Dong, and Y. Xia, Age and gender differences in the self-esteem of Chinese children. The Journal of Social Psychology, 137(3), 1997, 374-379.

12. M. H. S. Hamid, M. Shahrill, R. Matzin, S. Mahalle, and L. Mundia, Barriers to mathematics achievement in Brunei secondary school students: Insights into the roles of mathematics anxiety, selfesteem, proactive coping, and test stress. International Education Studies, 6(11), 2013, 1-14.

13. V. Helgeson, Psychology of gender (New York: Routledge, 2016).

14. V. Sherrow, For appearance' sake: The historical encyclopaedia of good looks, beauty, and grooming (Westport, CT: Oryx Press, 2001)

15. S. Jain, S., and M.P. Dixit, Self-esteem: A gender based comparison and the causal factors reducing it among Indian youth. International Journal of Humanities and Social Science invention, 3, 2014, 9-15.

16. T. Sowell, Education: Assumptions versus history (Stanford, CA: Hoover Institution Press, 1986). 
17. J. Bempechat, and A.T. Wells, Trends and issues in urban and minority education: Promoting the achievement of at-risk students (Trends and Issues No. 13). New York, NY: ERIC Clearinghouse on Urban Education (ERIC Document Reproduction services NO. ED315484, 1989).

18. D. H. Demo, S. A. Small and R.C. Savin-Williams, Family relations and the self-esteem of adolescents and their parents. Journal of Marriage and the Family, 49(4), 1987, 705-715.

19. A. Deshpande and M. Chhabriya, Parenting styles and its effects on adolescents' self-esteem. International Journal of Innovations in Engineering and Technology, 2(4), 2013, 310-315.

20. K.E. Bolger, C.J. Patterson, and J.B. Kupersmidt, J.B., Peer relationships and self-esteem among children who have been maltreated. Child Development, 69(4), 1998, 1171-1197.

21. A. Furnham, and H. Cheng, H., Perceived parental behaviour, self-esteem and happiness. Social Psychiatry and Psychiatric Epidemiology, 35(10), 2000, 463-470.

22. U.K. Moksnes and G.A. Espnes, Self-esteem and life satisfaction in adolescents-gender and age as potential moderators. Quality of Life Research, 22(10), 2013, 2921-2928.

23. M.R. Leary, L.S. Schreindorfer, and. A.L. Haupt, The role of low self-esteem in emotional and behavioral problems: Why is low self-esteem dysfunctional? Journal of Social and Clinical Psychology, 14(3), 1995, 297-314.

24. P.H. Silverstone, Is chronic low self-esteem the cause of eating disorders? Medical Hypotheses, 39, 1992, 311-315.

25. J.F. Sowislo, and U. Orth, Does low self-esteem predict depression and anxiety? A meta-analysis of longitudinal studies. Psychological Bulletin, 139(1), 2013, 213-240.

26. M. Bolognini, B. Plancherel, W. Bettschart and O. Halfon, Self-esteem and mental health in early adolescence: Development and gender differences. Journal of Adolescence, 19(3), 1996, 233-245.

27. E.J. Ginter, and P.L. Dwinell, The importance of perceived duration: Loneliness and its relationship to self-esteem and academic performance. Journal of College Student Development, 35(6), 1994, 456460.

28. P. Barrett, M. Webster and J. Wallis, Adolescent self-esteem and cognitive skills training: A schoolbased intervention. Journal of Child and Family Studies, 8(2), 1999, 217-227.

29. P. Haney, and J.A. Durlak, Changing self-esteem in children and adolescents: A meta-analytical review. Journal of Clinical Child Psychology, 27(4), 1998, 423-433.

30. S. Sharma, and S. Agarwala, Self-esteem and collective self-esteem among adolescents: An interventional approach. Psychological Thought, 8(1), 2015. Retrieved from http://psyct.psychopen.eu/article/view/121/html

31. V. Dani, Enhancement of adolescents' self-esteem by intervention module. Indian Journal of Health and Well-being, 6(2), 2015, 207-211.

32. M. Rosenberg, Conceiving the self (Krieger: Malabar, FL, 1986).

33. D. Shaffer, Social and personality development (Belmont, CA: Wadsworth, Cengage Learning, 2008).

34. P.C. Siah, Perceived parental sex discrimination, happiness and self-esteem: Children's perspective. Vulnerable Children and Youth Studies: An International Interdisciplinary Journal for Research, Policy and Care, 10(4), 2015, 314-320.

35. G. Nelson, The relationship between dimensions of classroom and family environments and the selfconcept, satisfaction and achievement of grade 7 and 8 students. Journal of Community Psychology, 12(3), 1984, 276-287.

36. M.S. Birkeland, K. Breivik, and B. Wold, Peer acceptance protects global self-esteem from negative effects of low closeness to parents during adolescence and early adulthood. Journal of Youth and Adolescence, 43(1), 2014, 70-80.

37. S.D. Litwack, J.W. Aikins, and A. Cillessen, A., The distinct roles of sociometric and perceived popularity in friendship: Implications for adolescent depressive affect and self-esteem. Journal of Early Adolescence, 32 (2), 2012, 226-251.

38. P. Van den Berg, J. Mond, M. Eisenberg, D. Ackard, and D. Neumark-Sztainer, The link between body dissatisfaction and self-esteem in adolescents: Similarities across gender, age, weight status, race/ethnicity, and socioeconomic status. Journal of Adolescent Health. 47(3), 2010, 290-296.

39. S. Dixit, G.G. Agarwal, J.V. Singh, S. Kant, and N. Singh, A study on consciousness of adolescent girls about their body image. Indian Journal of Community Medicine, 36(3), 2011, 197-202.

40. T.E. Davidson, and M.P. McCabe, Adolescent body image and psychosocial functioning. The Journal of Social Psychology, 146, 2006, 15-30.

41. L. Festinger, A theory of social comparison processes Human Relations, 7(2), 1954, 117-140.

42. F. Gibbons, and B. Buunk, Individual differences in social comparison: Development of a scale of social comparison orientation. Journal of Personality and Social Psychology, 76(1), 1999, 129-142. 
43. B. Buunk, H. Kuyper and Y. Van Der Zee, Affective response to social comparison in the classroom. Basic and Applied Social Psychology, 27(3), 2005, 229-237.

44. L. G. Aspinwall, and S.E. Taylor, Effects of social comparison direction, threat, and self-esteem on affect, self-evaluation, and expected success. Journal of Personality and Social Psychology 64 (5), 1993, 708-722. 